\title{
Article
}

\author{
Doi 10.5943/sif/6/1/8
}

\section{A rare medicinal fungus, Lignosus rhinocerus (Polyporales, Agaricomycetes), new to India}

\section{Vinjusha N and Arun Kumar TK}

The Zamorin's Guruvayurappan College (affiliated to the University of Calicut), Kerala 673014, India

Vinjusha N, Arun Kumar TK 2021 - A rare medicinal fungus, Lignosus rhinocerus (Polyporales, Agaricomycetes) new to India. Studies in Fungi 6(1), 151-158, Doi 10.5943/sif/6/1/8

\begin{abstract}
Lignosus rhinocerus is one of the most valuable medicinal fungi used throughout South East Asia, and South China. The polypore is characterized by a stipitate basidiomata with orbicular pileus, and an underground sclerotium, a trimitic hyphal system bearing generative hyphae with clamp connections, and globose to subglobose basidiospores. Basidiomata, including the sclerotia of $L$. rhinocerus are used to treat various ailments. L. rhinocerus is rarely encountered in the wild and has a very restricted geographic distribution. Because of its rarity and importance, domestication and commercial cultivation of the fungus has been attempted. During study of the polyporoid fungi in forests of Kerala State, India, some interesting specimens were collected. Detailed taxonomic study of the collected specimens identified them as L. rhinocerus, with a distribution record new to India. Taxonomic account of the species is presented.
\end{abstract}

Key words - Polyporaceae - sclerotia - taxonomy - therapeutic - tiger milk mushroom

\section{Introduction}

Lignosus rhinocerus (Cooke) Ryvarden is a polypore fungus belonging to the family Polyporaceae of the order Polyporales, Basidiomycota. The species is commonly known as "the tiger milk mushroom", since according to popular belief; its fruit bodies are often encountered in a forest region where a tigress drips its milk during feeding (Nallathamby et al. 2018). Lignosus rhinocerus is variously known as "beteskismas", "tish am ong", "Pèti' Aa", "cendawansusurimau" (Malaysia), "Ndurabi" (Indonesia), "how guikou or hurulingzhi" (China, which literary means "tiger milk Ganoderma"), and "hijiritake" (Japan) in local languages (Hilton \& Dhitaphichit 1978, Lee \& Chang 2007, Lee et al. 2012, Yap et al. 2013, Nallathamby et al. 2018). Morphologically, the species is characterized by centrally stipitate basidiomata, brownish pileus surface that are finely tomentose to glabrous, poroid hymenium, stipe always arising from an underground sclerotium, trimitic hyphal system with clamped generative hyphae, and smooth, ellipsoid, hyaline, inamyloid basidiospores (Núñez \& Ryvarden 2001). The sclerotia of L. rhinocerus are irregularly shaped, with leathery flesh, composed of white mycelia (Lai et al. 2013). Lignosus rhinocerus grows either on the ground, or on highly rotten wood (Ryvarden \& Johansen 1980, Núñez \& Ryvarden 2001, Tan et al. 2013).

The closely related species of L. rhinocerus are L. sacer (Afzel. ex Fr.) Torrend, L. tigris Chon S. Tan, L. cameronensis Chon S.Tan, and L. hainanensis B.K. Cui (Tan et al. 2013). L. tigris and L. cameronensis were recently discovered from Malaysia by Tan et al. (2013). So far, eight species are described in the genus (Index Fungorum 2021). Lignosus rhinocerus has close morphological similarities with Pleurotus tuber-regium (Fr.) Singer (Nallathamby et al. 2018). Recently, the use of molecular characters has aided in accurate taxonomic delimitation of these 
species. Sotome et al. (2008) used rpb2 gene region as a molecular marker for identifying L. rhinocerus. Later, Cui et al. (2011) and Tan et al. (2013) used ITS sequence data for identifying L. rhinocerus and the related Lignosus species. These studies present the phylogenetic placement of the species among its relatives. In the study by Tan et al. (2013), the highest genetic distance among Lignosus species was observed between L. rhinocerus and L. ekombitii Douanla-Meli.

Lignosus rhinocerus is considered as one of the most valuable medicinal fungi in South East Asia, and Hainan Province, China and is used for treating several ailments (Tan et al. 2010, Eik et al. 2012, Yap et al. 2013). Sclerotia of the species are used to treat breast cancer, fever, cough, asthma, and food poisoning (Lee et al. 2012). Various bioactive components are known to be present in the sclerotia of $L$. rhinocerus. Among the different bioactive components, polysaccharide protein complexes, and $\beta$-glucans possess anti tumour (Lai et al. 2008), and immunomodulatory activities (Wong et al. 2011). The anti cancer effect of the species is attributed to the presence of secondary metabolites, with ant oxidative and cytotoxic effects against cancer cells (Lau et al. 2014). Chinese physicians use the sclerotia of the species to treat liver cancer, chronic hepatitis, and gastric ulcers (Wong \& Cheung 2008). The species is also known to possess anti coagulant, anti inflammatory, anti microbial, anti diabetic, anti viral, anti obesity, fibrinolytic, hepatoprotective, and neuroprotective effects (Mohanarji et al. 2011, Nallathamby et al. 2018, Yap et al. 2018).

Lignosus rhinocerus is reported to have many ethnobotanical uses (Nallathamby et al. 2018). The species is used by various indigenous people as antipyretic, general tonic, starve off hunger, and wound healing (Tan 2009, Eik et al. 2012). L. rhinocerus is regarded as the "national treasure mushroom" by people of Malaysia. In Malaysia, native women consume L. rhinocerus sclerotia after childbirth. The presence of L. rhinocerus is believed to promise a good crop harvest, and for this reason the "Semai" natives of Malaysia use sclerotia of the species during paddy farming with prayer rituals (Nallathamby et al. 2018). As part of this belief, sometimes, the basidiocarp of $L$. rhinocerus are placed inside flowerpots, and filled with crops like paddy. A part from the indigenous people, L. rhinocerus is also well known among the urban population in Malaysia (Hattori et al. 2007). Basidiomata grounded and mixed with Chinese wine were used for external applications (Chang \& Lee 2004). The sclerotium was also consumed raw with betel leaves to get rid of cough and sore throat. Decoctions made from L. rhinocerus are believed to improve general wellness by enhancing alertness, vitality and energy (Sabaratnam et al. 2013).

Lignosus rhinocerus has a geographically isolated distribution, and is known only from tropical South China, Thailand, Malaysia, Sri Lanka, Indonesia, Philippines, Papua New Guinea, New Zealand, Australia, and subtropical Japan (Núñez \& Ryvarden 2001, Lai et al. 2011, Nallathamby et al. 2018). Because of the scattered distribution, and rarity in occurrence in the wild, several attempts have been undertaken to commercially cultivate, and domesticate this highly medicinal polypore (Lau et al. 2014). As a result, large scale cultivation of L. rhinocerus in a controlled environment has been recently established in Malaysia (Tan 2009, Lau et al. 2011, 2013, 2015). Occurrence and distribution of L. rhinocerus in other tropical regions of the world remains unknown.

During exploratory studies on the polypore fungi of Kerala State, India, an interesting collection was obtained. Morphological study and molecular phylogenetics revealed the identity of the species as L. rhinocerus. Taxonomic account of the species is presented.

\section{Materials \& methods}

\section{Morphology}

The basidiocarps were collected from forest areas of the Kerala region of Western Ghats in India, during the south west monsoon seasons of the year 2019. Macroscopic characters of fresh specimens were recorded. Online Auction Color Chart (2004) was used for noting the colour of the basidiomata. Microscopic observations were made on materials stained using aqueous solutions of $3 \%$ phloxine and $1 \%$ congo red, and mounted in $5 \%$ aqueous $\mathrm{KOH}$. Reaction of the basidiospores on treatment with Melzer's reagent and cotton blue was noted. Twenty basidiospores from each 
specimen were measured for obtaining the spore dimensions, range of spore quotient (Q, length/width ratio) and its mean value $\left(\mathrm{Q}_{\mathrm{m}}\right)$. A LABOMED Lx400 compound light microscope was used for observing the microscopic preparations, and for taking measurements of the fungal structures. All collections examined are deposited at the ZGC herbarium, India.

\section{Molecular characterization}

For DNA extraction from the specimen (ZGCVN903), NucleoSpin® Plant II kit (MachereyNagel 2014, Germany) was used. PCR amplification of LSU gene region was carried out using the primers LROR and LR5. Sequencing was done using BigDye Terminator v3.1 Cycle sequencing Kit (Applied Biosystems, USA). The sequencing PCR temperature profile consisted of a 1st cycle at $96^{\circ} \mathrm{C}$ for 2 minutes, followed by 30 cycles at $96^{\circ} \mathrm{C}$ for $30 \mathrm{sec}, 50^{\circ} \mathrm{C}$ for $40 \mathrm{sec}$, and $60^{\circ} \mathrm{C}$ for 4 minutes. The newly generated LSU sequence was deposited in the GenBank database (www.ncbi.nlm.nih.gov) with accession number (MW721128). Sequence similarity assessments were conducted using BLAST search in NCBI's GenBank nucleotide database (https://blast.ncbi.nlm.nih.gov/). The newly generated sequences and those taken from GenBank were aligned using MEGA X64 (Kumar et al. 2018). The LSU dataset consisted of 10 taxa. Daedaleopsis confragosa (Bolton) J. Schröt. was selected as an outgroup taxon for the dataset following Tan et al. (2013). Maximum Likelihood (ML) analysis was conducted with MEGA X64 using Tamura-Nei model (Tamura \& Nei 1993). Phylogeny test was carried out using boot bootstrap method, based on 1000 bootstrap replicates. The aligned sequence data matrix was deposited in TreeBase (Submission ID: 27882, Reviewer access URL:

http://purl.org/phylo/treebase/phylows/study/TB2:S27882?x-access

code $=1768 f 5 b d 672 \mathrm{c} 6 \mathrm{e} 52 \mathrm{db} 11073 \mathrm{f} 29 \mathrm{~d} 34809 \&$ format=html).

\section{Results}

\section{Taxonomy}

Lignosus rhinocerus (Cooke) Ryvarden, Norw. J1 Bot. 19: 232 (1972)

Basionym: Polyporus rhinocerus Cooke, Trans. \& Proc. Bot. Soc. Edinb. 13: 150 (1879)

Synonyms:

Fomes rhinocerus (Cooke) Sacc. [as 'rhinocerotis'], Syll. fung. (Abellini) 6: 152 (1888)

Scindalma rhinocerus (Cooke) Kuntze, Revis.gen. pl. (Leipzig) 3 (3): 519 (1898)

Polyporus sacer var. rhinocerus (Cooke) Lloyd, Mycol. Writ. 6 (Letter 65): 1037 (1920)

Polystictus rhinocerus (Cooke) Boedijn, Bull.Jard. bot. Buitenz, 3 Sér. 16 (4): 390 (1940)

Microporus rhinocerus (Cooke) Imazeki, Bull.Gov. Forest Exp. Stn Tokyo 57: 113 (1952)

Index Fungorum number: IF316915, Faceoffungi number: FoF09471

Fig. 1

Basidiomata annual, large sized, solitary, hard and tough, centrally stipitate, up to $200 \mathrm{~mm}$ tall. Pileus $150 \mathrm{~mm}$ in diameter, $60 \mathrm{~mm}$ thick, circular in outline, narrowly infundibuliform, conectrically zonate, weakly sulcate, radially wrinkled, yellowish brown (OAC820), with a greenish tint due to presence of algae, yellowish shades fades on drying, margin paler, wavy to lobed, thin. Hymenophore poroid. Pores 5-8 per mm, angular, irregular, absent along margin, minutely tuberculate, dirty white, brownish on bruising. Context $2 \mathrm{~mm}$ thick, creamish white, homogenous. Stipe $100 \mathrm{~mm}$ long, up to $15 \mathrm{~mm}$ thick, cylindrical, even with underground sclerotium, stipe surface having some irregular depressions, glabrous, light brown, tissue, cream, appear as more or less hollow. Sclerotium irregularly elongated, up to $80 \mathrm{~mm}$ long, cream, dirty and soiled, bone hard especially on drying. Odour not distinctive. Spore print not observed.

Basidiospores 3-4.5 $\times 1.5-2 \mu \mathrm{m}, \mathrm{L}=3.5, \mathrm{~W}=1.97 \mathrm{Q}=1.5-2, \mathrm{Q}_{\mathrm{m}}=1.8$, subcylndrical to broadly ellipsoid, hyaline, thin walled, guttulate or eguttulate, coloured in aqueous solutions of $3 \%$ 
phloxine and $1 \%$ congo red mixture, acyanophilic in cotton blue, inamyloid in Melzer's reagent. Basidia not observed. Cystidia absent. Hymenial trama interwoven, and trimitic. Generative hyphae 2-3 $\mu \mathrm{m}$ wide, hyaline, thin walled, smooth, rarely branched, with clamp connections. Skeletal hyphae 2-4 $\mu \mathrm{m}$ wide, hyaline smooth, thick walled $(1 \mu \mathrm{m})$, frequently branched, mostly without lumen. Binding hyphae present, $1.5-3 \mu \mathrm{m}$ wide, hyaline to very pale brown, thick walled (up to $1 \mu \mathrm{m}$ ), frequently branched, with a wide to narrow lumen. Pileal trama interwoven. Generative hyphae 2-3 $\mu \mathrm{m}$ wide, hyaline, smooth, thin walled, branched, with clamp connections. Skeletal hyphae predominant, $2-5 \mu \mathrm{m}$ wide, hyaline to pale brown, thick walled $(1 \mu \mathrm{m})$, branched. Binding hyphae 2-3 $\mu \mathrm{m}$ wide, hyaline to pale brown, branched, mostly without lumen. Pileipellis interwoven at base to form short, more or less agglutinated trichodermal patches, that are 10-25 $\mu \mathrm{m}$ long, made of hyphae $2-4 \mu \mathrm{m}$ wide, hyaline and solid. Stipe trama interwoven. Generative hyphae 2-3 $\mu \mathrm{m}$ wide, hyaline, smooth, thin walled, branched, with clamp connections. Skeletal hyphae predominant, 2-7 $\mu \mathrm{m}$ wide, hyaline, thick walled (up to $2 \mu \mathrm{m}$ ), rarely branched, septations not observed. Binding hyphae less frequent, $2-5 \mu \mathrm{m}$ wide, hyaline, highly branched, thick walled and solid. Stipitipellis similar as pileipellis, more agglutinated trichoderm than pileipellis, each hyphae 2-4 $\mu \mathrm{m}$ wide, hyaline.

Material examined - India, Kerala State, Kollam district, Thenmala, Thenmala forest, on the ground, 23 September 2019, Vinjusha N, ZGCVN903.

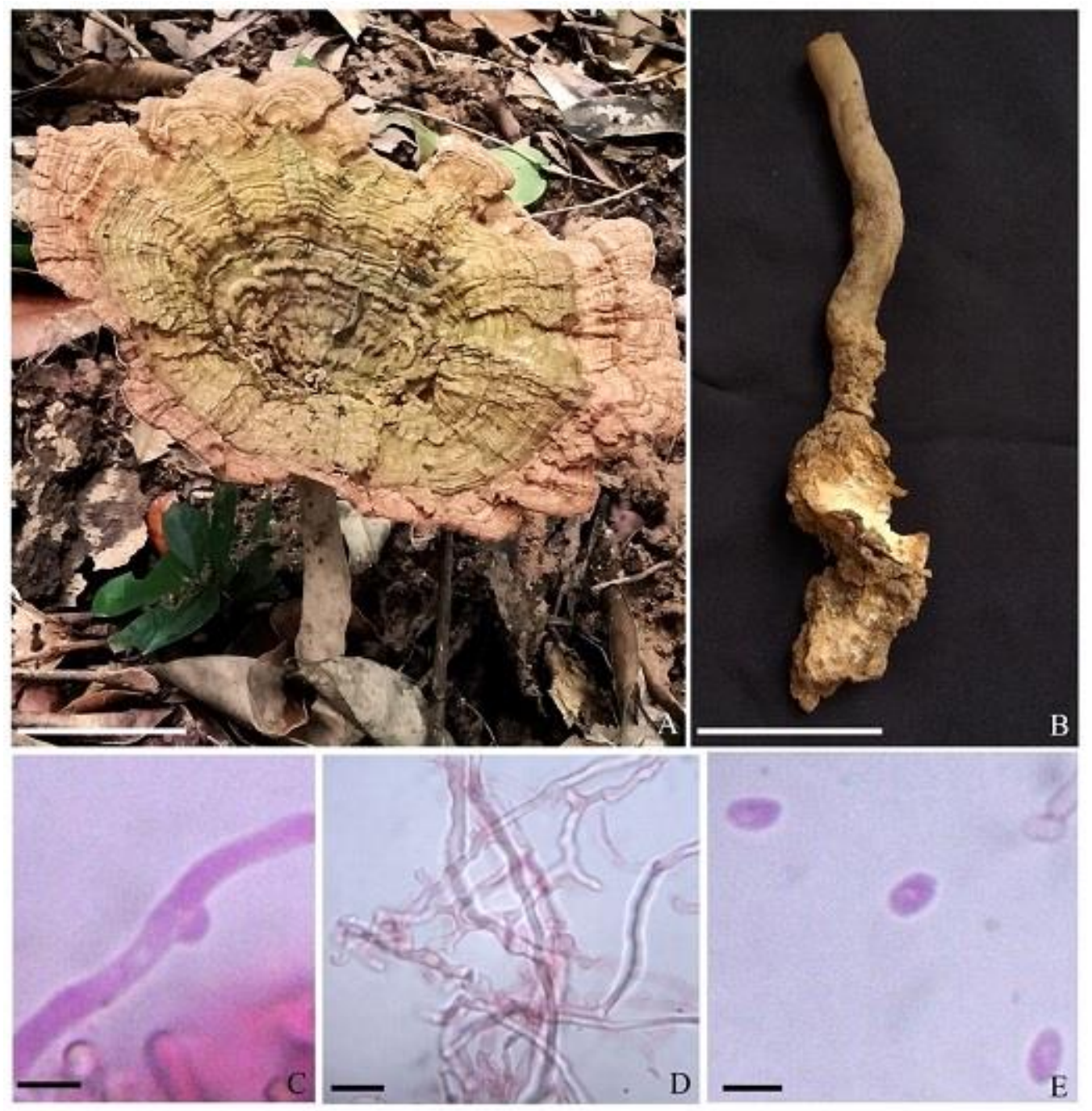

Fig. 1 - A Basidiomata of Lignosus rhinocerus. B Stipe showing sclerotium. C Generative hyphae showing clamp connection. D Binding hyphae. E Basidiospores. Scale bars: $A=30 \mathrm{~mm}, \mathrm{~B}=50$ $\mathrm{mm}, \mathrm{C}=4 \mu \mathrm{m}, \mathrm{D}=8 \mu \mathrm{m}, \mathrm{E}=4 \mu \mathrm{m}$. 


\section{Molecular characterization}

BLAST search using the LSU sequence of the specimen ZGCVN903 resulted in 100\% identity with three accessions of L. rhinocerus from Malaysia and China (GenBank numbersKX900694, FJ899146, FJ899145). The phylogenetic tree (Fig. 2) shows the placement of our collection within the genus. In the phylogenetic tree, our collection clustered with accessions of $L$. rhinocerus with $95 \%$ bootstrap support.

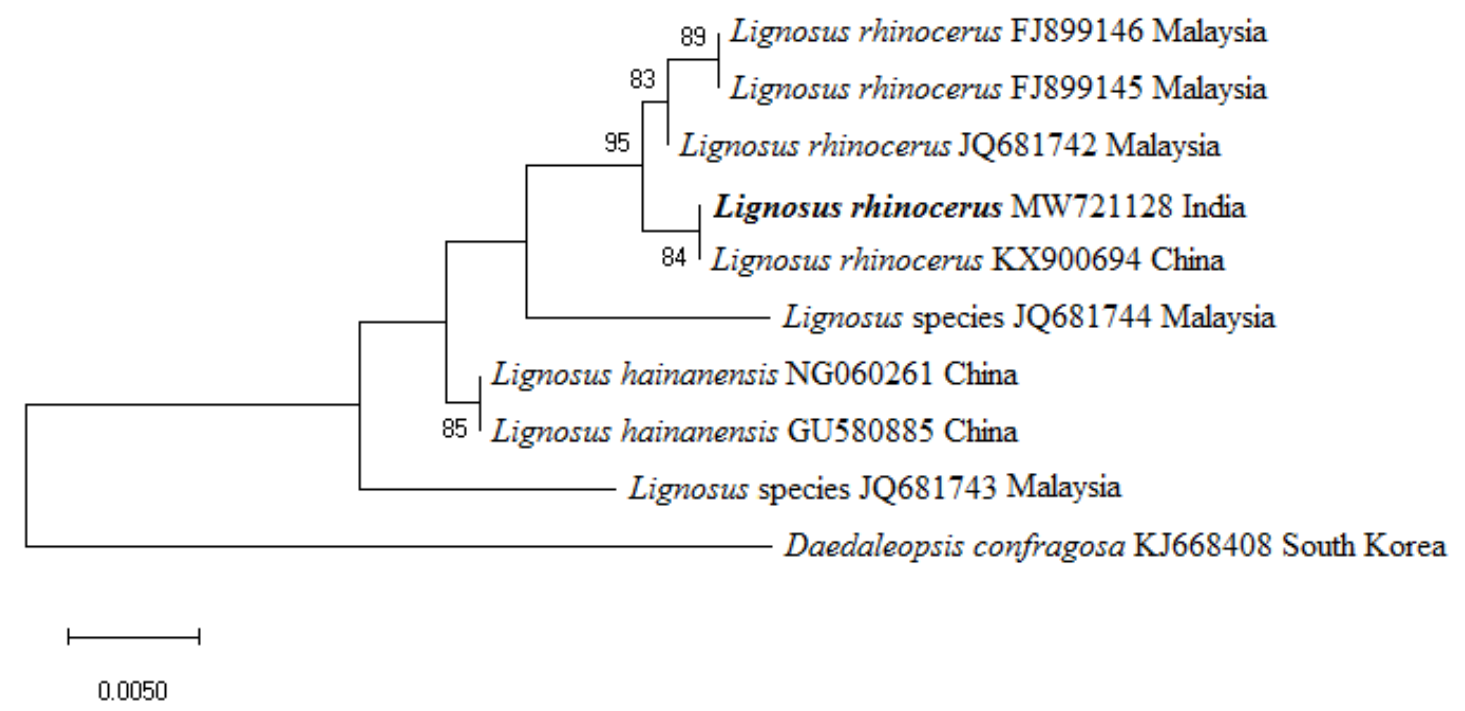

Fig. 2 - Maximum likelihood tree generated using LSU sequence data. Values at the nodes indicate Maximum Likelihood bootstrap values. Bootstrap values above 50\% are shown. Bold names represent the collection from Kerala, India. GenBank accession numbers and voucher localities are given along with the taxa.

\section{Discussion}

Morphological characters like, a centrally stipitate basidiomata, with irregular sclerotia, and the small hyaline ellipsoid basidiospores undoubtedly place the present specimen as Lignosus rhinocerus. The species $L$. dimiticus Ryvarden also produces basidiomata with similar pore size (6-8 per $\mathrm{mm})$ and spore size $(3-4.5 \times 2.5-3 \mu \mathrm{m})$ (according to the description by Ryvarden 1975). However, the former is distinguished from our collection in having a dimitic hyphal system, and lacks binding hyphae. Lignosus tigris is another close species, but, possesses larger pores (1-2 per mm; Tan et al. 2013). Another species, L. sacer (Fr.) Torrend, also resembles L. rhinocerus in morphology. However, L. sacer produces larger basidiospores $(5-7 \times 3-4.5 \mu \mathrm{m}$; Ryvarden 1972).

Our molecular phylogenetic analysis (Fig. 2) strongly supports the identity of our collection as $L$. rhinocerus. In the phylogenetic tree, accession of Kerala collection of L. rhinocerus showed higher affinity with the accession of the species from China (with 83\% bootstrap support). In the present analysis, L. hainanensis B.K. Cui is the sister species, in accordance with the previous phylogenetic studies of the species by Cui et al. (2011) and Tan et al. (2013).

Lignosus rhinocerus is distributed in tropical to subtropical regions of Asia (Núñez \& Ryvarden 2001, Nallathamby et al. 2018). The species is known only from certain geographical regions such as South China, Japan, Sri Lanka, Indonesia, The Philippines, Thailand, Malaysia, Indonesia, Philippines, Papua New Guinea, New Zealand, and Australia (Ryvarden \& Johansen 1980, Nallathamby et al. 2018). India has a rich mycobiota of wood rotting fungi as evident from published literature (Butler \& Bisbi 1931, Banerjee 1947, Vasudeva 1960, Roy \& De 1996, Leelavathy \& Ganesh 2000, Sharma 2000, Prasher 2015). However, L. rhinocerus has not been reported from the country so far. Hence, the present study is the first documentation report of the 
rare and medicinal $L$. rhinocerus from India. The present study indicates that $L$. rhinocerus may be having a wider distribution than previously known.

\section{Acknowledgements}

Vinjusha N. acknowledges support from the Kerala State Council for Science, Technology and Environment (KSCSTE) in the form of a research fellowship. The authors thank the Chief Conservator of Forests \& Chief Wildlife Warden, Kerala, for permission for field work in the forest areas of Kerala.

\section{References}

Banerjee SN. 1947 - Fungus Flora of Calcutta and suburbs-I. Bulletin of the Botanical Society of Bengal 1: 37-54.

Butler EJ, Bisby GR. 1931 - The Fungi of India, Scientific monograph no I. ICAR, Delhi, 237 p.

Chang YS, Lee SS. 2004 - Utilisation of macrofungi species in Malaysia. Fungal Diversity 15: 1522. Doi 10.1.1.459.4963

Cui BK, Tang LP, Dai YC. 2011 - Morphological and molecular evidences for a new species of Lignosus (Polyporales, Basidiomycota) from tropical China. Mycological Progress 10: 267271. Doi 10.1007/s11557-010-0697-y

Eik LF, Naidu M, David P, Wong KH et al. 2012 - Lignosus rhinocerus (Cooke) Ryvarden: A medicinal mushroom that stimulates neurite outgrowth in PC-12 Cells. Evidence-Based Complementary and Alternative Medicine, 7 p. Doi 10.1155/2012/320308

Hattori T, Noraswati M, Salmiah U. 2007 - Basidiomycota: diversity of Malaysian polypores. Pp 55-68, in Malaysian Fungal Diversity, eds S. Jones, E.B.G. Hyde, and K.D. Vikineswary, Malaysian Fungal Diversity, University of Malaya and Ministry of Natural Resources and Environment, Malaysia.

Hilton RN, Dhitaphichit P. 1978 - Procedures in Thai ethnomycology. Natural History Bulletin of the Siam Society 41: 75-92.

Index Fungorum. 2021 - www.indexfungorum.org (Accessed on March 11, 2021)

Kumar S, Stecher G, Li M, Knyaz C, Tamura K. 2018 - MEGA X: Molecular evolutionary genetics analysis across computing platforms. Molecular Biology and Evolution 35: 1547-1549. Doi 10.1093/molbev/msy096.

Lai CKM, Wong KH, Cheung PCK. 2008 - Anti-proliferative effects of sclerotial polysaccharides from Polyporus rhinocerus Cooke (Aphyllophoromycetideae) on different kinds of leukemic cells. International Journal of Medicinal Mushrooms 10: 255-264.

Doi 10.1615/IntJMedMushr.v10.i3.60.

Lai WH, Loo SS, Rahmat N, Shaharuddin S et al. 2013 - Molecular phylogenetic analysis of wild tiger's milk mushroom (Lignosus rhinocerus) collected from Pahang, Malaysia and its nutritional value and toxic metal content. International Food Research Journal 20: 2301-2307.

Lai WH, SitiMurni MJ, Fauzi D, Abas Mazni O, Saleh NM. 2011 - Optimal culture conditions for mycelial growth of Lignosus rhinocerus. Mycobiology 39: 92-95.

Doi 10.4489/MYCO.2011.39.2.092

Lau BF, Aminudin N, Abdullah N. 2011- Comparative SELDI-TOFMS profiling of lowmolecular-mass proteins from Lignosus rhinocerus (Cooke) Ryvarden grown under stirred and static conditions of liquid fermentation. Journal of Microbiological Methods 87: 56-63. Doi 10.1016/j.mimet.2011.07.005

Lau BF, Abdullah N, Aminudin N. 2013 - Chemical composition of the tiger's milk mushroom, Lignosus rhinocerotis (Cooke) Ryvarden, from different developmental stages. Journal of Agriculture and Food Chemistry 61: 4890-4897. Doi 10.1021/jf4002507

Lau BF, Abdullah N, Aminudin N, Lee HB, et al. 2014 - The potential of mycelium and culture broth of Lignosus rhinocerotis as substitutes for the naturally occurring sclerotium with 
regard to antioxidant capacity, cytotoxic effect, and low-molecular-weight chemical constituents. PLoS ONE 9: e102509. Doi 10.1371/journal.pone.0102509

Lau BF, Abdullah N, Aminudin N, Lee HB, Tan PJ. 2015 - Ethnomedicinal uses, pharmacological activities, and cultivation of Lignosus spp. (tiger's milk mushrooms) in Malaysia- A review. Journal of Ethnopharmacology 169: 441-458. Doi 10.1016/j.jep.2015.04.042

Lee SS, Chang YS. 2007 - Ethnomycology in Malaysia. Pp. 307-317 in E. B. G. Jones, KD Hyde, and V. Sabaratnam (eds), Malaysian Fungal Diversity, University of Malaya and Ministry of Natural Resources and Environment, Malaysia.

Lee ML, Tan NH, Fung SY, Tan CS, Ng ST. 2012 - The anti proliferative activity of sclerotia of Lignosus rhinocerus (tiger milk mushroom). Evidence-Based Complementary and Alternative Medicine, 5 p. Doi 10.1155/2012/697603

Leelavathy KM, Ganesh PN. 2000 - Polypores of Kerala. Daya Publishing House. Chawla Offset Printers, $164 \mathrm{p}$.

Macherey-Nagel. 2014 - NucleoSpin® Plant II: Genomic DNA from Plant User manual, June 2014/Rev.03. Macherey-Nagel GmbH \& Co. KG. Düren.

Mohanarji S, Dharmalingam S, Kalusalingam A. 2011 - Screening of Lignosus rhinocerus extracts as antimicrobial agents against selected human pathogens. Journal of Pharmaceutical and Biomedical Sciences 18: 1-4.

Nallathamby N, Phan CW, Seow SLS, Baskaran A et al. 2018 - A status review of the bioactive activities of tiger milk mushroom Lignosus rhinocerotis (Cooke) Ryvarden. Frontiers in Pharmacology 8: 998. Doi 10.3389/fphar.2017.00998

Núñez M, Ryvarden L. 2001 - East Asian polypores 2. Polyporaceae s. lato. Synopsis Fungorum 14: $170-522$.

Online Auction Color Chart. 2004 - The Online Auction Color Chart. The New Language of Color for Buyers and Sellers. 12 color charts +2 pp text.

Prasher IB. 2015 - Wood-rotting non-gilled Agaricomycetes of Himalayas. Springer Netherlands, 653 p. Doi 10.1007/978-94-017-9858-7

Roy A, De AB. 1996 - Polyporaceae of India, International Book Distributor, Dehradun, India, 287.

Ryvarden L. 1972 - A critical checklist of the Polyporaceae in tropical East Africa. Norwegian Journal of Botany. 19: 229-238.

Ryvarden L. 1975 - Studies in the Aphyllophorales of Africa 3.Three new polypores from Zaïre. Bulletin du Jardin Botanique National de Belgique 45: 197-203.

Ryvarden L, Johansen I. 1980 - A preliminary polypore flora of East Africa. Fungiflora, Oslo, 630 p.

Sabaratnam V, Wong KH, Naidu M, David PR. 2013 - Neuronal health-can culinary and medicinal mushrooms help? Journal of Traditional Complementary Medicine 3: 62-68.

Doi 10.4103/2225-4110.106549

Sotome K, Hattori T, Ota Y, To-anun Cet al. 2008 - Phylogenetic relationships of Polyporus and morphologically allied genera. Mycologia 100: 603-615. Doi 10.3852/07-191R

Sharma JR. 2000 - Genera of Indian polypores. BSI, Northern Circle, Dehra Dun, 188 p.

Tamura K, Nei M. 1993 - Estimation of the number of nucleotide substitutions in the control region of mitochondrial DNA in humans and chimpanzees. Molecular Biology and Evolution 10: $512-526$.

Tan CS. 2009 - Setting up pilot plant for up scaling production of 'Tiger Milk' mushroom as dietary functional food. Technical Report MOATF0109M004, Government of Malaysia.

Tan CS, Ng ST, Tan J. 2013 - Two new species of Lignosus (Polyporaceae) from Malaysia L. tigris and L. cameronensis. Mycotaxon 123: 193-204. Doi 10.5248/123.193

Tan CS, Ng ST, Vikineswary S, Lo FP, Tee CS. 2010 - Genetic markers for identification of a Malaysian medicinal mushroom, Lignosus rhinocerus (cendawansusurimau). Acta Horticulturae 859: 161-167. Doi 10.17660/ActaHortic.2010.859.19 
Vasudeva RS. 1960 - The fungi of India (revised edition of Butler and Bisby's work). ICAR, New Delhi, 552 p.

Wong KH, Cheung PCK. 2008 - "Sclerotia: emerging functional food derived from Mushrooms," in Mushrooms as Functional Foods, P. C. K. Cheung, Ed., 111-146 p, John Wiley \& Sons, Hoboken, NJ, USA.

Wong KH, Lai CKM, Cheung PCK. 2011 - Immunomodulatory activities of mushroom sclerotial polysaccharides. Food Hydrocolloids 25: 150-158. Doi 10.1016/j.foodhyd.2010.04.008

Yap HYY, Tan NH, Ng ST, Tan CS, Fung SY. 2018 - Inhibition of protein glycation by tiger milk mushroom [Lignosus rhinocerus (cooke) Ryvarden] and search for potential anti-diabetic activity related metabolic pathways by genomic and transcriptomic data mining. Frontiers in Pharmacology 9: 103. Doi 10.3389/fphar.2018.00103

Yap HYY, Tan N, Fung SY, Aziz AA et al. 2013 - Nutrient composition, antioxidant properties, and anti-proliferative activity of Lignosus rhinocerus Cooke sclerotium. Journal of the Science of Food and Agriculture, 2945-2952. Doi 10.1002/jsfa.6121 